\title{
Secondary Evaluation of Hydrogel Lens Implants
}

\author{
BRUCE A. NOBLE*, J. MICHAEL HAYWARD*, CHRISTOPHE HUBER
}

Leeds and Zurich

\begin{abstract}
Summary
Objective-To review patients currently forming part of a study of poly 2 hydroxyethylmethacrylate (P-HEMA) 'Hydrogel' intraocular lenses.

Design-Patients were taking part in the Hydrogel arm of a prospective trial at Scarborough Hospital. Recruitment was by letter.

Setting-District General Hospital.

Patients-One hundred and eight from the Scarborough trial in whom a Hydrogel lens had been implanted.

Interventions-An independent assessment was carried out at a median interval of 20 months following surgery. Visual acuities were assessed with best possible refraction and the eyes examined both before and after pupil dilation.

Main outcome measures-Visual acuity and major complications.

Results-91\% had visual acuities of $6 / 9$ or better and $30 \%$ achieved $6 / 5$. In $61 \%$ the central area ( $3 \mathrm{~mm}$ diameter) of posterior capsule was clear but $39 \%$ had signifcant fibrosis or pearl formation in this area and $8 \%$ had undergone posterior capsulotomy. Five major decentrations had taken place, one of which occurred following a spontaneous rupture of the posterior capsule $17.6 \%$ of patients showed significant pigment dispersion behind the IOL either on the posterior capsule or in the anterior vitreous that could not be accounted for purely by surgical trauma. An atonic iris sphincter was noted in $17 \%$ of eyes.

Conclusions-This lens gives good visual results but its stability and tendency to cause pigment shedding need to be closely monitored.
\end{abstract}

The term hydrogel refers to a broad class of polymeric materials that swell in water (greater than $20 \%$ ) but do not dissolve in water. It has been suggested that for intraocular lens manufacture it has certain advantages over PMMA that include hydrophilicity, softness, flexibility, autoclavability and resistance to Nd:YAG-laser induced damage. ${ }^{1}$

The use of hydrogel material for the manufacture of lens implants is relatively new and represents a major development in lens material and design. It is one of the first style of lenses that can be inserted folded through a small incision. An independent assessment of results is crucial before the lens is widely launched and adopted: Many trials involve 'best case' analysis and this gives opportunities for important complications to be overlooked and for startling successes to be overstated.

We have therefore investigated a group of patients who have undergone standardised and high quality surgery by the same surgeon. The performance of the lens and the eventual outcome for each patient are properly comparable and can be directly related to the lens material and design. We were kindly invited by Mr. Piers Percival of Scarborough 
Hospital to review patients in whom an Alcon hydrogel lens had been implanted. These patients were forming part of his own prospective study of Hydrogel versus PMMA lens implants. $^{2}$

\section{Patients and Methods}

The hydrogel lens implanted was the singlepiece biconvex lens described by Barrett: ${ }^{3}$ $6 \mathrm{~mm}$ in diameter, $12 \mathrm{~mm}$ long and $6.5 \mathrm{~mm}$ wide, the long axis gently curving forward (Fig. 1). They were inserted in their hydrated state (38\% water) and were not folded. The surgery was all performed by Mr. Percival. The technique used was a modification of the endocapsular method of Galand, with bag placement of the IOL. ${ }^{4}$

Percival's assessment of his patients was a 'best case' analysis. 150 had been entered into the Hydrogel arm of the trial but 25 had been excluded per or post-operatively on the basis of trial criteria. However we adopted the 'intention to treat' policy suggested by Hampton $^{5}$ which avoids 'best case' analysis and we aimed to re-examine as many of the original 150 cases whether or not they were still in the trial. Using the trial records the 137 patients who had not either died or moved away from the area were asked by letter to attend Scarborough Hospital for the purpose of an independent assessment and $79 \%$ did so (Table I).

Patients attending were reviewed and fully examined by two of the authors (BAN and

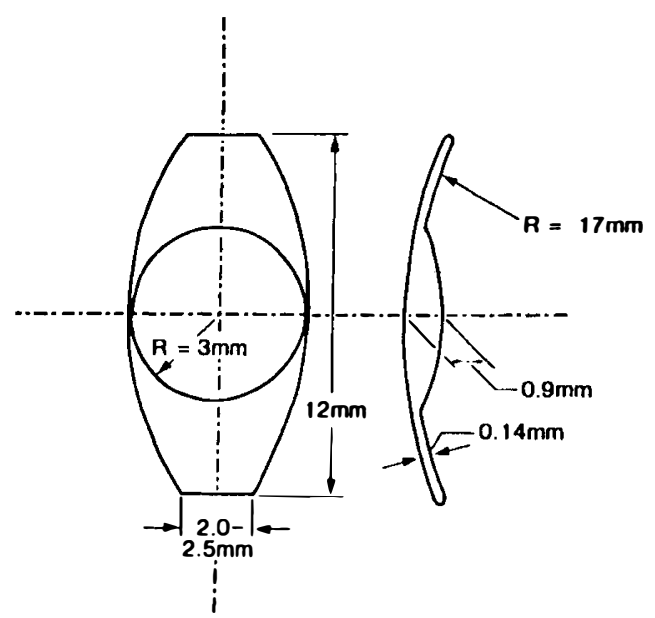

Fig. 1. The IOGEL $L_{T M}$ posterior chamber lens (courtesy Alcon Laboratories)
JMH). Visual acuities were assessed with best possible refraction and the anterior segment examined both before and after pupil dilation. The retina was also examined.

\section{Results}

The average age of patients at the time of surgery was 73 years (range $49-52$ years) and the mean follow-up time 20 months (range 11-30 months).

\section{Visual Acuity}

Table II shows corrected visual acuity. 91\% had visual acuities of $6 / 9$ or better and $30 \%$ achieved $6 / 5$. Fourteen out of 36 patients in the $6 / 9$ group had pathology responsible for reducing visual acuity: posterior capsule opacity or pigment (10), age related macular degeneration (2), retinal venous occlusion (1) and cyclitic membrane formation (1). Table III shows the causes of visual loss in patients whose acuities were $6 / 12$ and below. Of the latter group four out of ten could not be attributed to the surgical event.

\section{Major Complications \\ Per-operative}

Two patients had a major posterior capsule break necessitating the insertion of a sulcus fixated conventional posterior chamber lens. One patient had a zonular rupture, another a small accidental posterior capsulotomy and in both of these patients a hydrogel lens had been inserted (in the former case into the sulcus). These two patients had both done well although the sulcus fixated lens had a $1 \mathrm{~mm}$ decentration.

Post-operative

One patient had an iris prolapse repaired.

Table I Scarborough hydrogel patients

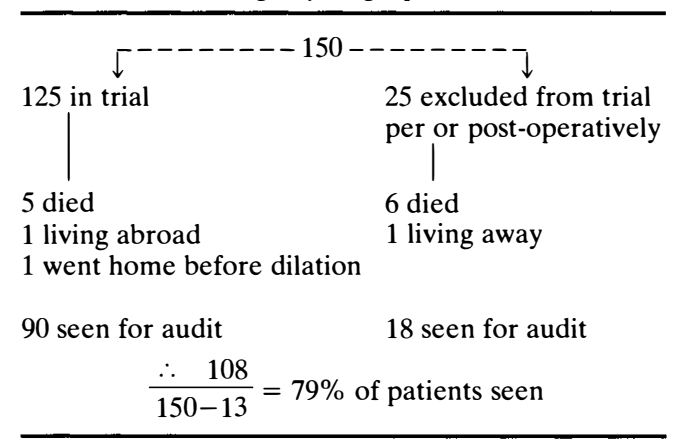


Table II Visual acuity

\begin{tabular}{lrl}
\hline $6 / 5$ & 32 & $30 \%$ \\
$6 / 6$ & 30 & $28 \%$ \\
$6 / 9$ & 36 & $33 \%$ \\
$6 / 12$ & 4 \\
$6 / 18$ & 1 \\
$6 / 24$ & 2 \\
$6 / 36$ & 1 \\
$6 / 60$ & 1 \\
C.F. & 1
\end{tabular}

Four patients in this group, for various reasons, had a conventional PMMA PC lens in situ at the time of this survey. They have been included in the visual results and complications sections only.

Two lenses had dislocated into the vitreous after surgery, one spontaneously the other following Nd:YAG capsulotomy. Three other lenses had dislocated requiring further surgical intervention (vide infra). One patient had severe visual loss following a fibrinoid uveitis. Eleven other patients had suffered severe post-operative uveitis that had since settled [personal communication]. One other cyclitic membrane was noted but with a clear visual axis and visual acuity of $6 / 9$. However AC activity of $5-10$ cells per $1 \mathrm{~mm} \times 3 \mathrm{~mm}$ field was noted in $7 \%$ of all patients.

\section{Effects of the Lens on the Eye}

Secondary Capsulotomy

Nine patients $(8 \%)$ had undergone secondary $\mathrm{Nd}$ :YAG laser capsulotomy. In addition there were 10 other patients whose visual acuity was slightly reduced and in whom, it was judged, a capsulotomy would result in an improvement, although eight of these had a visual acuity of $6 / 9$. One patient showed laser-induced pitting of the lens.

Table III Cause of reduced visual acuity

\begin{tabular}{|c|c|c|}
\hline$V A$ & $\begin{array}{c}\text { No. of } \\
\text { patients }\end{array}$ & Diagnosis \\
\hline $6 / 12$ & 4 & $\begin{array}{l}\text { Age related macular degeneration } \\
\text { Dilated pupil due to atonic iris } \\
\text { sphincter }\end{array}$ \\
\hline $6 / 18$ & 1 & Posterior capsule opacity \\
\hline $6 / 24$ & 2 & $\begin{array}{l}\text { Posterior capsule opacity } \\
\text { Cystoid macular oedema }\end{array}$ \\
\hline $6 / 36$ & 1 & Central retinal vein occlusion \\
\hline $6 / 60$ & 1 & $\begin{array}{l}\text { Cystoid macular oedema following } \\
\text { post-operative endophthalmitis }\end{array}$ \\
\hline C.F. & 1 & Central retinal vein occlusion \\
\hline
\end{tabular}

Posterior capsule opacity

Sixty-one per cent of the patients had a clear central area of posterior capsule. Twentythree per cent of central areas were affected by capsular fibrosis and $23 \%$ by epithelial pearls.

\section{Pigment Disperson (Table IV)}

Eight per cent of patients had significant anterior (iris) and $18 \%$ significant posterior (posterior capsule and vitreous) pigment disperson (Fig. 2). However of the four eyes which had an IOP of over $24 \mathrm{mmHg}$ only one had significant pigment dispersion. The effect of lens placement on pigment dispersion is shown in Table V.

\section{Pupil abnormalities}

The most striking pupil abnormality was that of an atonic sphincter leading to mid to markedly dilated pupils in $17 \%$ of patients. This was noted in the absence of any signs of surgical sphincter damage. It led to a reduction in visual acuity in one patient but several others commented on the problem of glare.

\section{Effect of the Eye on the Lens}

Decentration (Table V)

Five lenses were either decentred or dislocated requiring further surgical intervention. One was associated with a wound leak. Of the two other major decentrations, one lens was repositioned into the sulcus, the other exchanged. Two lenses had dislocated into the vitreous, one following a Nd:YAG capsulotomy, the other (Figs 3 and 4) following a spontaneous capsular tear four months after surgery. The lens in this case was lying on, and seemed to be adherent to, the retina.

Thirty-four lenses were slightly decentred ( 23 by $0.5 \mathrm{~mm}, 11$ by $1 \mathrm{~mm}$ ) although these were not giving rise to visual problems. Two patients had undergone further surgical inter-

Table IV Pigment dispersion

$\left.\begin{array}{ccc}\hline \text { Grade } & \text { Ant. Segment } & \text { Post. Segment } \\ \hline 0 & 48 & 74 \\ 1 & 34 & 8 \\ 2 & 17 & 7 \\ 3 & 6 \\ 4 & 3\end{array}\right\} 8 \% \quad \begin{gathered}3 \\ \end{gathered}$




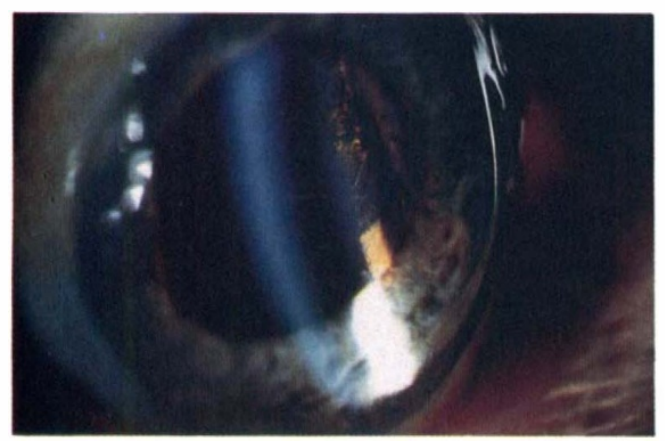

Fig. 2. Posterior segment pigment shedding.

vention for ' $\mathrm{C}$ deformity' (vide supra). Another 3\% had a minor ' $\mathrm{C}$ ' deformmity which was not affecting ocular function. Two per cent had a degree of lens buckling although this did not amount to the ' $\mathrm{S}$ ' deformity reported with silicone lenses.

\section{Lens placement (Table VI)}

Gonioscopy was not carried out in this survey, but it was possible to comment on lens placement in the majority of cases because of the generous anterior capsule flaps.

\section{Lens Quality}

Nine of the lenses had defects that appeared to be due either to manufacturing faults or to an in vivo effect on the lens material (Figs 5 and 6); surface sheen (4), anterior surface 'bronze deposition' (2), other fine surface markings (2) and one line defect. In addition there was one 'pock mark' caused by introducing forceps. Although these lenses are known to have an opalescent appearance this was marked in only $23 \%$; even in these cases it had no effect on visual acuity.

\section{Discussion}

The following parameters of a new lens design, using a new material, were judged to be paramount in assessing its safety and per-

Table $\mathbf{V}$ The effect of lens placement on pigmentation

\begin{tabular}{lc}
\hline Lens placement & Overall pigment score per lens \\
\hline Bag & 1.1 \\
Laag $\frac{1}{2}$ Sulcus & 2.6 \\
Sulcus & 2.4 \\
Uncertain & 1.4 \\
\hline
\end{tabular}

formance: visual acuity, major complications, the effect of the lens on the eye, the effect of the eye on the lens, and lens quality.

\section{Visual Acuity}

It was found that this lens gave excellent visual results despite its opalescence. Ninetyone per cent of patients achieved $6 / 9$ or better and $30 \%$ achieved $6 / 5$ even on the basis of 'intention to treat' rather than 'best case' analysis. The many differing ways of recording results makes comparison between trials difficult ${ }^{5}$ but these results were no worse than other trials where authors recorded results of $85-95 \%$ achieving 6/9.3,6 and 7

\section{Effect of the Lens on the Eye}

The clarity of the posterior capsule in the majority of eyes was good and this was reflected in the low capsulotomy rate of $8 \%$. Others have quoted significant posterior capsule opacification of $12-15 \%{ }^{3,7}$ However reports $^{3,8}$ of only a $1-3 \%$ capsulotomy rate may have been rather premature. Hydrogel lenses are certainly capable of suffering lens marking during Nd:YAG laser capsulotomy, although it is said that they are more resilient to this than a PMMA lens. ${ }^{9}$

Whereas iris-clip lenses not infrequently dislocated into the vitreous it was alarming to see that one lens was adherent to the retina with a definite area of atrophy marking the

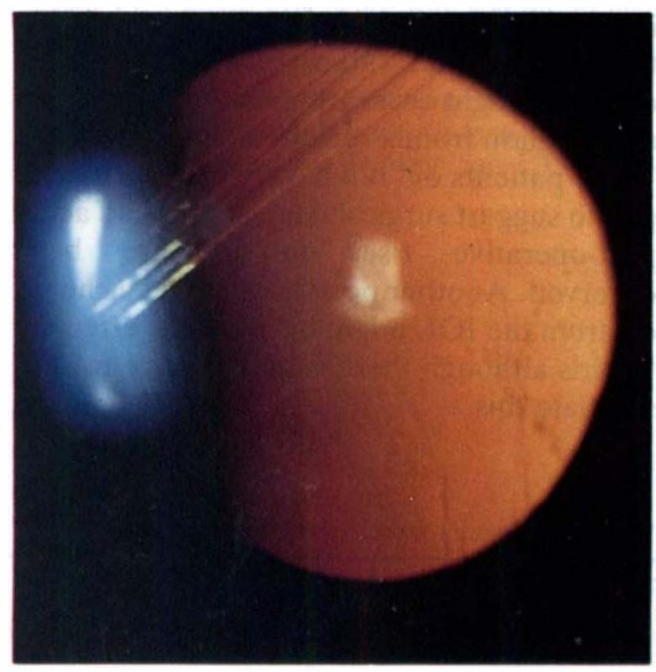

Fig. 3. Spontaneous rupture of the posterior capsule. 


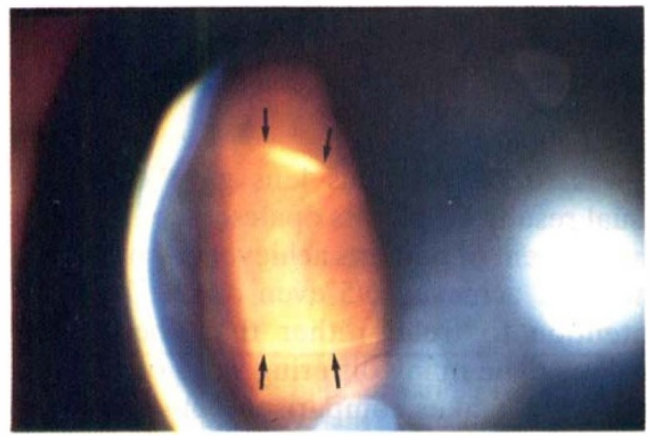

Fig. 4. Lens lying on the retina (edges identified by arrows).

border of contact. It is impossible to predict the long term sequelae of this. We understand [personal communication] that one of these lenses (implanted at another centre) has had to be removed piecemeal from the retinal surface via a vitrectomy procedure.

No case of pigment dispersion was found by Mehta in his study. ${ }^{10}$ However in this series it was a ştriking phenomenon. Lenses that were still truly bag fixated showed less pigment shedding (Table V). Others have reported incidences of 26 to $37 \%$ although in the latter case the lenses were sulcus fixated..$^{6,7}$ This was attributed to the failure of the posterior lens vault to prevent iris chaffing.

Atonic pupils have not been reported before as a failure of soft lens implants. However the syndrome is recognised with other implants ${ }^{11,12}$ with the site of the lesion being the iris sphincter rather than a neurogenic cause (as might occur from damage to the ciliary ganglion from a retrobulbar anaesthetic). These patients did not have marked iris atrophy to suggest surgical damage nor had acute post-operative rises in pressure been observed. Another possibility is that a chemical from the IOL might have a toxic effect on the iris although there is no evidence to substantiate this.

Table VI Lenses decentred according to placement

\begin{tabular}{ll}
\hline Bag & $17 \%$ \\
$\frac{1}{2} \mathrm{gBag} \frac{1}{2}$ Sulcus & $68 \%$ \\
Sulcus & $25 \%$ \\
Uncertain & $30 \%$ \\
\hline
\end{tabular}

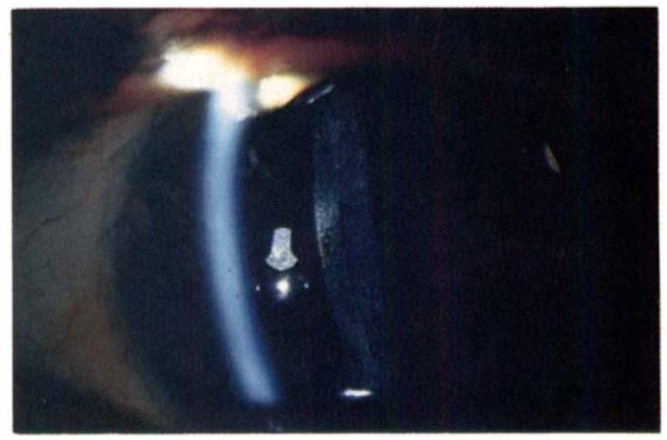

Fig. 5. Surface "bronzing" (this is not pigment).

Major Complications/Effect of the Eye on the Lens

Although the incidence of lens decentration does not seem to be unduly high or have an effect on visual acuity there was an unacceptable rate of lens displacement leading to two patients being rendered aphakic and three needing surgical repositioning of the lens and all within 6 months following surgery. This was a prototype lens of length $12 \mathrm{~mm}$ and it may be that this is too long for some eyes. Surgeons have changed from bag to sulcus fixation for soft silicone lenses for this reason. ${ }^{13}$ Conversely, there have been reports of these lenses being too small for some eyes and a 'windscreen wiper lens' has been the end result. A hydrogel lens that comes to lie $\frac{1}{2} \mathrm{bag} /$ $\frac{1}{2}$ sulcus has a greater chance of significant decentration $(68 \%$ of such placementsTable VII). Almost all of the lenses in this study were intended for bag placement and checked for this at the time of surgery. How-

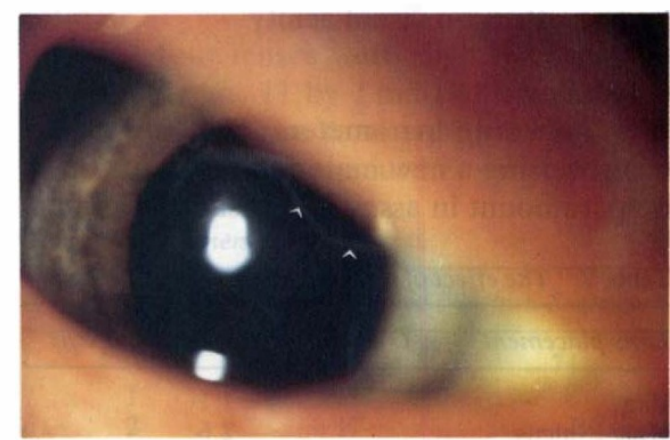

Fig. 6. Line defect (arrow). The other mark is a photographic processing error. 
Table VII Lens placement

\begin{tabular}{lll}
\hline Bag & 54 & $52 \%$ \\
$\frac{1}{2}$ Bag $\frac{1}{2}$ Sulcus & 25 & $24 \%$ \\
Sulcus & 12 & $12 \%$ \\
Uncertain & 13 & $12 \%$ \\
\hline
\end{tabular}

ever from the results of bag/sulcus position (Table IV) it would seem that one of the haptics (probably the upper one) is capable of escaping from the bag with time. The lens capsule does not form adhesions with polyHEMA lenses unlike their PMMA counterparts. There is theoretical evidence to suggest that the use of a linear capsulotomy may result in the equatorial region of the capsule being breached with consequent weakening of the upper part of the capsular bag and displacement of the implant. Capsulorhexis may overcome this problem by giving more stable bag fixation which seems the ideal for stability and decreased pigment disperson.

\section{Conclusion}

Poly-HEMA is an exciting new material. It may have less potential than PMMA to harm the corneal endothelium. ${ }^{14}$ Although these 'Hydrogel' lenses gave good visual results we have reservations about their safety and will continue to do so until the problems of lens size, displacement and surgical management of the capsular bag have been resolved. The results of the newer lens of length $11.5 \mathrm{~mm}$ are awaited with interest.

We are grateful to Mr. Piers Percival for his open handed approach in allowing us to scrutinise his patients and for tolerating the disruption that this entailed to his out-patient clinic in Scarborough.

\section{References}

${ }^{1}$ Allarakhia L, Knoll RL, Lindstrom RL: Soft intraocular lenses. J Cataract Refract Surg 1987, 13: 607-20.

${ }^{2}$ Percival SPB. Prospective study comparing hydrogel with PMMA lens implants. (In press.)

${ }^{3}$ Barratt GD, Beasley H, Lorenzetti OJ. Rosenthal A: Multicenter trial of an intraocular hydrogel lens implant. J Cataract Refract Surg 1987, 13: 621-6.

${ }^{4}$ Percival SPB: Capsular bag implantation of the hydrogel lens. J Cataract Refract Surg 1987, 13: $627-9$.

${ }^{5}$ Hampton JR: Presentation and analysis of the results of clinical trials in cardiovascular disease. $\mathrm{Br} \mathrm{J}$ Med 1981, 282: 1371-3.

${ }^{6}$ Neuman AC and Cobb B: Advantages and limitations of current soft intraocular lenses. J Cataract Refract Surg 1989, 15: 257-63.

${ }^{7}$ Menapace. J Cataract Refract Surg 1989, 15: 264-71.

${ }^{8}$ Percival SPB: Early experience with soft hydrogel implants. Eye 1987, 1: 735-7.

${ }^{9}$ Skelnik DL, Lindstrom RL, Tamulinas C, Lorenzetti OJ: Nd:YAG laser interaction with Alcon IOGEL hydrogen intraocular lenses: An in vitro toxicity assay. J Cataract Refract Surg 1987, 13: 662-8.

${ }^{10}$ Mehta KR, Sathe SN, Karyekar SD: The new soft intraocular lens implant. Am Intra-Ocular Implant Soc J 1978, 4: 200-4.

${ }^{11}$ Percival SPB: Results after intracapsular extraction: the atonic pupil. Ophthalmic Surg 1977, 8: $138-43$.

${ }^{12}$ Lam S, Beck RW, Hall D, Creighton B: Atonic pupil after cataract surgery. Ophthalmol 1989, 96: 589-90.

${ }^{13}$ Chen TT: Clinical experience with soft intraocular lens implantation. J Cataract Refract Surg 1987, 13: $50-3$.

${ }^{14}$ Yalon M, Blumenthal M, Goldberg EP: Preliminary study of hydrophilic intraocular lens implants in cats. Am Intraocular Implant Soc J 1984, 10: $315-17$. 